\title{
ФОРМИРОВАНИЕ НОВОГО ТИПА ПЕДАГОГА, ОБЛАДАЮЩЕГО КРЕАТИВНОЙ КОМПЕТЕНТНОСТЬЮ
}

\section{FORMATION OF NEW TYPE OF TEACHER, HAVING CREATIVE COMPETENCE}

I. Bryakova

Summary: The article studies the important issue of forming a new type of a teacher-philologist, having the creative competence; the method suggests involving the teacher into the process of the competence formation within the University methodological system. The formation stages of student-philologists' creative competence are singled out; they display stage-inherent criteria and indices which can be analyzed and measured.

The methodological system is based on a large-scale experiment to identify the types of a teacher according to the level of creativity. The methodological proficiency in the development of literature and creative skills in students and the ability to create the text determine the level of creativity. The typology of the teachers-philologists correlates with the stages of students' creative competence formation. The article proves the efficiency of the students-philologists training due to identification of creative competence stages.

The author used such methods of research as interview, questionnaire, biographical method, R. Johnson's test, J. Guilford's test, J. Renzulli's test, S. Mednik's test, proprietary technologies.

Keywords: teacher-philologist's professional competence, teacherphilologist's creative competence, student-philologist's creative competence, criteria and indices, stages of a student-philologist's creative competence formation, typology of teachers according to creativity levels.

\author{
Брякова Ирина Евгеньевна \\ Д.п.н., профессор, Оренбургский государственный \\ педагогический университет \\ ibryakova@yandex.ru
}

Аннотация: В статье раскрывается актуальная проблема формирования нового типа учителя-словесника, обладающего креативной компетентностью, через включение будущего учителя-словесника в методическую систему формирования данной компетентности в педагогическом вузе. В процессе исследования были выделены стадии формирования креативной компетентности студентов-филологов, в которых отражены критерии и показатели данной компетентности, повторяемые на определённых этапах, что дало возможность их замера и изменения.

В основе построения методической системы лежит широкомасштабный эксперимент по выделению типологии учителей по уровню креативности, определяемой по владению ими методикой развития литературно-творческих способностей учащихся и умению создать свой текст. Типология учителей-словесников соотнесена со стадиями сформированной креативной компетентности студентов-филологов педагогического вуза и сделан вывод 06 эффективности подготовки учителя-словесника нового типа.

Методы исследования: интервьюирование и анкетирование, метод биографического исследования, тесты Р. Джонсона, Дж. Гилфорда и Дж. Рензулли, С. Медника, авторские методики.

Ключевые слова: профессиональная компетентность учителя-словесника, креативная компетентность учителя-словесника, студента-филолога; критерии и показатели, стадии формирования креативной компетентности студента-филолога; типология учителей по уровню креативности.

Это новый тип педагога, обладающий креативной компетентностью, нестандартно мыслящий, способный увлечь своим предметом, расширить горизонты познания учащегося, самореализующийся в педагогической деятельности и реализующий потенциально креативные способности ученика.

Креативную компетентность учителя - словесника и студентов-филологов определим как интегральное многофакторное качество личности, обусловливающее на профессиональной основе развитие литературнотворческих способностей школьников и саморазвитие собственных творческих способностей (Брякова, 2008, 2010).

В последнее десятилетие появились работы, развивающие идею креативной компетентности педагога, в частности монография "Креативность как ключевая ком- 
петентность педагога" под ред. М.М. Кашапова, Т.Г. Киселёвой, Т.В. Огородовой (Ярославль, 2013), в которой креативная компетентность педагога рассматривается как надпрофессиональная компетентность [9]. Модель формирования креативной компетентности будущего педагога в научном сотворчестве рассматривает в своём диссертационном исследовании А.Г. Шумовская (2013). К особенностям креативной компетентности учителей начальных классов обращаются Т.В. Суняйкина, Ю.А. Сергиенко (2015), проблему формирования креативной компетенции и креативной компетентности бакалавров педагогического образования в процессе обучении математики исследовали И.С. Егорова $(2012,2016)$, И.С. Бекешева (2017).

Мы рассматриваем креативную компетентность педагога как самостоятельное новообразование, находящееся в сложных диалектических связях с профессиональной компетентностью. Учитель может быть профессионально компетентен, но обладать разными способностями к творчеству, разной готовностью к развитию данных способностей у своих учеников. Мы считаем, что, находясь в сложных диалектических связях с профессиональной компетентностью, креативная компетентность может как совпадать, так и расходиться с ней.В основе этой позиции, доказанной нами в ходе исследования и длительного эксперимента, проведённого в 2008-2010 годах [5,6]и подтверждённого в 2019 году, лежит идея Т.Г. Браже о нетождественности понятий «педагогическое мастерство» и «педагогическое творчество»: если дефицит знаний стимулирует развитие «педагогического творчества», то последнее в конечном итоге является мощным стимулом развития «педагогического мастерства» [4], что и дало повод к разграничению понятий «креативная компетентность» и «профессиональная компетентность» педагога [5,6].

Педагогическая деятельность как творческий процесс вызывала интерес у исследователей всегда. К этой проблеме в разное время обращались учёные-методисты Т.Г. Браже [2,3,4], А.М. Антипова, Е.О. Галицких [8], В.Г. Маранцман, Е.К. Маранцман, Н.М. Свирина, И.В. Сосновская, А.Г. Кутузов, Н.А.Миронова [11], Е.С. Романичева, Е.С. Роговер, Н.П. Терентьева, Е.И. Целикова, Е.Р. Ядровская и др., психологи Ф.Н. Гоноблин, Н.В. Кузьмина, Н.Д. Левитов, А.К. Маркова, С.Л. Рубинштейн и др.; педагоги В.И. Андреев, В.И. Загвязинский, В.А. КанКалик, М.Е. Кудрявцева [10], А.В. Мудрик, И.В. Муштавинская [12], Н.Д. Никандров, М.М. Поташник, В.Г. Рындак, М.Н. Скаткин, В.А. Сластёнин, философ А.И. Субетто [14], В.С. Шубинский и др.

В методике литературы средней школы накоплен достаточно большой опыт развития творческих способностей учеников. Данной проблеме посвящены исследования методистов: Т.Г. Браже [2,3], О.Ю. Богдановой, Н.Р. Бершадской, М.П. Воюшиной, В.А. Доманского, С.А.
Зинина, М.Г. Качурина, В.Я. Коровиной, Е.А. Корсунского, А.Г. Кутузова, С.А. Леонова, В.Г. Маранцмана, Е.К. Маранцман, Д.Н. Мурина, Г.С. Меркина, Е.С. Роговера, Н.М. Свириной [13], И.В. Сосновской, Е.Р. Ядровской [15] и др. Этот опыт, несомненно, ценный, но не обеспечивает в полной мере профессиональную деятельность учителей, так как не ориентирован на обучение студентов развитию литературно-творческих способностей школьников.

Творческая личность педагога формируется в педагогическом вузе. В нашем случае - в методической системе формирования креативной компетентности студентовфилологов, одним из принципов построения которой является ориентация на работу с текстом как продуктом творческой деятельности, а среди принципов функционирования - диалогичность; принцип ориентации на переход от интуитивного действия в ситуации неопределённости к осознанному решению задачи; этапность, учитывающая переход от подражанию к творчеству; установка на сотворчество, творческое саморазвитие.

Реализации системы способствуют метаnредметные креативные технологии. Основным средством обучения выступает текст (учебный, критический, художественный, публицистический) как продукт творческой деятельности студентов и под их руководством школьников.

Условием развития креативности студентов является наличие образца для подражания. Образец в лице преподавателя вуза, учителя не всегда может обладать высоким уровнем креативности, что с психологической точки зрения подтверждает идею о принципиальной незавершённости личности и мнение М.М. Бахтина об обретении собственной уникальности личности через диалог с «другим» [1].

Мы пришли к выводу, что формирование креативности - процесс гетерохронный и неравномерный. Выделенные нами стадии формирования креативной компетентности носят волнообразный, цикличный характер: репродуктивная, активизирующая, интегративная, творческая стадии последовательно переходят одна в другую, образуя новое ценностное качество личности.

Нами были разработаны критерии и показатели сформированности креативной компетентности студентов-филологов педагогического вуза. [Таблица 1]. Данные критерии измеряемы, объективны, в них отражены сущностные характеристики креативной компетентности, они повторяемы на определённых стадиях формирования креативной компетентности $[5,6]$.

В основе построения системы формирования креативной компетентности студентов-филологов лежит проведённый нами эксперимент - анализ образова- 
Таблица 1.

Критерии и показатели сформированности креативной компетентности студентов-филологов педагогического вуза

\begin{tabular}{|l|}
\multicolumn{1}{|c|}{ Критерии } \\
\hline 1. Потребность в самоактуализации, \\
самореализации, саморазвитии \\
через профессионально-творческую \\
деятельность
\end{tabular}

2. Способность к определению творческой задачи для успешного осуществления собственной методической деятельности

3. Способность студентов к созданию критического текста читателя-профессионала

\section{Показатели}

1. Наличие позитивных ожиданий в области профессионально-творческой деятельности

2. Открытость чужому опыту, восприимчивость и гибкость по отношению к творческой проблеме, творческой ситуации

3. Эмоциональная устойчивость в ситуации неопределённости и стремление к её разрешению

4. Способность к личностным изменениям при сохранении основополагающих ценностных установок

1. Выделение творческого противоречия в точках зрения на текст как предмет исследования, в жизни и суждениях героев литературного произведения

2. Формулирование вопроса или задания по тексту художественного произведения

3. Создание проблемной ситуации, стимулирующей творческую деятельность ученика

4. Создание новой методической концепции урока, творчески развивающей ученика, или модифицирование старой

1. Наличие собственной интерпретации художественного текста

2. Соответствие интерпретации текста авторской позиции и соотнесённость с ней собственной оценки произведения

3. Диалогичность и проблемность в характере оценивания студентом художественного текста

4. Использование широкого культурологического контекста

5. Композиционная стройность работы

6. Индивидуальность стиля и выразительность речи

4. Способность студентов к созданию художественного и публицистического текста

1. Наличие художественной образности, позволяющей раскрыть жанровую доминанту текста

2. Определение лейтмотива текста

3. Своеобразие интонации, определяющей текст и подтекст работы

4. Особенности стилистической и языковой выразительности

5. Композиционная стройность работы

5. Владение методическим инструментарием развития литературнотворческих способностей учеников

6. Способность студентов научить учеников создавать свой текст читателя-критика (анализ и интерпретацию художественного текста)

\section{1. Знание механизмов развития литературно-творческих способностей учащихся}

2. Знание методик развития литературно-творческих способностей учеников

3. Умение создавать локальные методики, ориентированные на литературно-творческое развитие учеников

Результативное использование методик, позволяющих ученикам создавать тексты, отвечающие следующим требованиям:

1. Отобранный учеником материал соответствует поставленной цели

2. Выделенная авторская позиция соотнесена с собственной позицией читателя

3. Выявлен смысл структурных элементов текста (сюжета и композиции, многозначности художественной детали, изобразительно-выразительных средств художественной речи)

4. Уместно и точно используется привлекаемый дополнительный материал, создающий контекст интерпретации.

5. Соблюдается композиционная стройность, логичность, ясность изложения

7. Способность студентов научить учеников создавать свой художественный и публицистический текст

\section{1. Степень самостоятельности учеников в создании текста}

2. Наличие в тексте учащихся художественной образности, позволяющей раскрыть жанровую специфику текста 3. Выразительность речи (богатство, уместность и правильность использования тропов)

4. Индивидуальность стиля (развёрнутость высказывания; точность, краткость речи; поток сознания)

5. Композиционная стройность работы

8. Способность студентов куверенным и эффективным действиям в ситуации неопределённости на уроках, во внеклассной работе по предмету
1. Готовность к эффективному использованию методик развития литературно-творческих способностей учеников 2. Создание специальных способов деятельности, отбор необходимых для данного случая

3. Готовность к эффективному переносу знаний, умений и навыков в новую ситуацию (эффективное использование филологической, культурологической, психолого-педагогической, методической компетенций, входящих в креативную компетентность студентов) тельной практики по выявлению типологии учителей по уровню креативности, по характеру и успешности их влияния на креативность обучаемых.

В широкомасштабном эксперименте приняли уча- стие 100 учителей и 1000 учеников г. Оренбурга, г. Кирова [5].Были определены диагностики и методики исследования: анкетирование и интервьюирование учителей, составление индивидуального творческого портрета учителя; диагностика креативности школьников по экс- 
пресс-методу Р. Джонсона (экспертная оценка креативных способностей учащихся) и методике Дж. Рензулли (самооценка креативных способностей); диагностика креативных способностей учеников по тесту Дж. Гилфорда «Словесная ассоциация», по методике «Определение понятий», адаптированной Т.А. Барышевой, по тесту отдалённых ассоциаций С. Медника, по авторским методикам «Создание текста», «Завершение фабулы», «Постановка проблемы».

В основу типологии учителей было положено владение ими методикой развития литературно-творческих способностей учащихся и умение учителя создать свой художественный, публицистический или критический текст, что является ядром креативной компетентности студентов и учителей-словесников.

Нами было выделено четыре muna учителей по уровню креативности [5].

В первую группу (первый тип, учитель-ретранслятор) вошли учителя, не владеющие методикой развития литературно-творческих способностей учеников и не занимающиеся сами литературным творчеством. Число респондентов составило 29\%. Возраст и стаж работы не влияют существенно на креативность учителей. Среди респондентов были учителя с трёх, пяти, четырнадцати, девятнадцати и двадцатилетним стажем работы.

Во вторую группу (второй тип, учитель-экспликатор) вошли учителя, владеющие методикой развития литературно-творческих способностей учеников, но сами не пишущие стихи, прозу. Это самая многочисленная группа респондентов - она составила 39\%. Учителя разных возрастов, стажа работы, квалификационных категорий, семейного положения. Педагогов этой группы отличает активная жизненная позиция, стремление участвовать в общественной жизни школы, определённая доля самолюбия и желание быть со своим классом первыми в учёбе и общественной деятельности. Именно учителя этой группы оказались организаторами школьных литературных вечеров, внеклассных мероприятий, связанных с литературной жизнью города. Они предприимчивы, инициативны, ответственны, переживают за результаты своего труда, рефлексивны. Учителя этого типа часто и охотно дают открытые уроки, ученики активно участвуют в олимпиадах, конференциях.

В третью группу (интуитивно-творческий тип, учитель-импровизатор) вошли учителя, не владеющие методикой развития литературно-творческих способностей учеников, но занимающиеся собственным литературным творчеством. Количество респондентов составило 14\%, меньше, чем в остальных группах. Люди творческие, стаж работы относительно небольшой, до прихода в школу работали в редакции газеты, где и продолжают сотрудничать, один учитель был заведующим литератур- ной частью в театре, кто-то работал в библиотеке, есть учителя, пришедшие в школу после работы в университете. Они ведут литературные кружки, литературные гостиные, драматические кружки, выпускают школьный литературный журнал, организуют конкурсы чтецов, ведут элективные курсы. Качество знаний у учеников этих учителей не всегда высокое, но интеллектуальный потенциал детей находится в постоянном возбуждении и развитии. Дети любят их за артистическую натуру, эмоциональную тонкость, оптимизм, оригинальность, творческую неожиданность и парадоксальность.

В четвёртую группу (учитель-исследователь) вошли учителя, владеющие методикой развития литературнотворческих способностей учеников и занимающиеся собственным литературным творчеством. Это тоже довольно многочисленная группа $-18 \%$. Личности яркие, сильные, незаурядные, в большинстве своём лидеры, любимые учениками.

Поскольку в общеобразовательной школе нами зафиксированы учителя с разным уровнем креативности, мы предположили, что принадлежность учителя к тому или иному типу можно закрепить в качестве тех конечных результатов, которых студент может достичь ещё в вузе в зависимости от своих индивидуальных способностей. Наше исследование подтвердило эти выводы $[5,6]$.

Таблица 2.

Сопоставление типологии учителей-словесников по уровню креативности со стадиями

сформированной креативной компетентности студентов-филологов 5 курса в \%

\begin{tabular}{|c|c|}
\hline $\begin{array}{l}\text { Типы учителей-словесников по } \\
\text { уровню креативности при n=100 }\end{array}$ & $\begin{array}{c}\text { Стадии сформированной } \\
\text { креативной компетентности } \\
\text { студентов-филологов педагоги- } \\
\text { ческого вуза в конце эксперимен- } \\
\text { тальной работы при n=78 }\end{array}$ \\
\hline $\begin{array}{l}\text { 1. Учитель-ретранслятор - } 29 \\
\text { 2. Учитель-экспликатор - } 39 \\
\text { 3. Учитель-импровизатор - } 14 \\
\text { 4. Учитель-исследователь - } 18\end{array}$ & $\begin{array}{l}\text { 1. Репродуктивная - } 6 \\
\text { 2. Активизирующая - } 18 \\
\text { 3. Интегративная - } 31 \\
\text { 4. Творческая - } 45\end{array}$ \\
\hline
\end{tabular}

Учитывая тот факт, что интегративная и творческая стадии сформированной креативной компетентности студентов ориентируют их на модель деятельности учителя-исследователя, можно утверждать, что профессиональная деятельность выпускников, обучавшихся по нашей методической системе, будет более успешной, что и подтвердил отсроченный эксперимент, проведённый нами в 2019 году.

Таким образом, когда мы говорим о формировании креативной компетентности студента-филолога, речь идёт о другом, более результативном качестве учительской работы. 


\section{ЛИТЕРАТУРА}

1. Бахтин М.М. Эстетика словесного творчества. М.: Искусство, 1979. 424 с.

2. Браже Т.Г. 0 литературе в школе. Книга для учителя. СПб.: Издательский дом "МИРС", 2008. 394 с.

3. Браже Т.Г. Гуманитарная культура взрослых: развитие в процессе непрерывного образования. СПб.: Тускарора, 2006. 164с.

4. Браже Т.Г. Развитие творческого потенциала и изучение профессионального мастерства учителя литературы: метод.рек./сост.Т.Г. Браже. АПН сССР, НИИ ООВ, Л., 1986. 36 С.

5. Брякова И.Е. Методическая система формирования креативной компетентности студентов-филологов педагогического вуза автореф. дис. ... докт. пед. наук С.-Петербург. 2010.51 c.

6. Брякова И.Е. Формирование креативной компетентности студентов-филологов педагогического вуза: монография. Оренбург: Изд-во 0ГПу, 2010.380 с.

7. Брякова И.Е. Методика развития литературно-творческих способностей школьников в процессе литературного образования // Методика обучения литературе в школе: учебник для студентов филологических факультетов педагогических вузов: в 2 кн. /сост. и общая ред. А-ра пед. наук, проф. Н.М. Свириной. Кн. 1. СПб.: Изд-во РГПУ им. А.И. Герцена, 2021. С.104 - 137.

8. Галицких Е.О. Мастерские жизнетворчества. Монография. Киров, 2016. 183 с.

9. Креативность как ключевая компетентность педагога /Под ред.проф. М.М. Кашапова, доц. Т.Г. Киселевой, доц. Т.В. Огородовой. Ярославль: ИПК«Индиго», 2013. 392 с.

10. Кудрявцева, М.Е. Учитель как субъект творчества. Монография. СПб.: НОу "Экспересс", 2006. 192с.

11. Миронова Н.А. Цифровые технологии обучения в контексте непрерывного литературного образования: монография. М.: Изд-во "экон-Информ", 2020. 147 c.

12. Муштавинская И.В. Рефлексивные технологии в обучении взрослых. СПб.: СПб АПП0, 2008. $96 c$.

13. Свирина Н.М. Методы и способы формирования пространства современного урока // Методика обучения литературе в школе: учебник для студентов филологических факультетов педагогических вузов: в 2 кн. /сост. и общая ред. д-ра пед.наук, проф. Н.М. Свириной. Кн. 2. СПб.: Изд-во РГПу им. А.И. Герцена, 2021. С.142-163.

14. Субетто А.И. Онтология и феноменология педагогического мастерства. Кн.1. Тольятти, 1999. 208с.

15. Ядровская Е.Р. Методика преподавания литературы: уроки в основной школе. Учебное пособие. М.: ЮРАЙТ, 2018. 236 с.

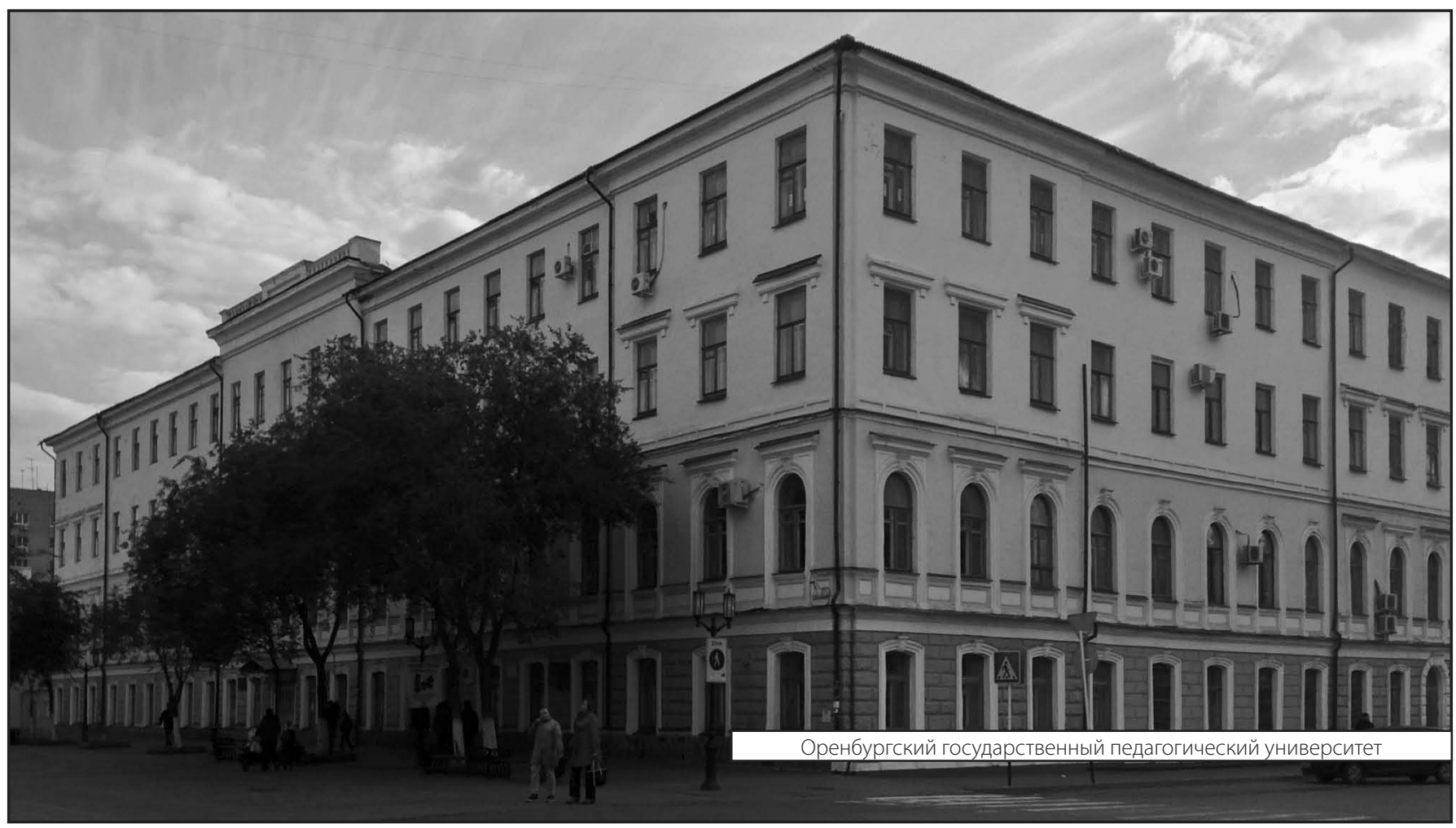

